\title{
Concepts and Technology of Flexible AC Transmission Systems
}

\author{
Keshav Kumar'1, Praveen Kumar², Kusum Meena1 \\ ${ }^{1}$ Student, ${ }^{2}$ Assistant Professor \\ 1,2Poornima College of Engineering, Jaipur, Rajasthan, India
}

\begin{abstract}
How to cite this paper: Keshav Kumar | Praveen Kumar | Kusum Meena "Concepts and Technology of Flexible Ac Transmission Systems" Published in International Journal of Trend in Scientific Research and Development (ijtsrd), ISSN: 24566470, Volume-3 | Issue-3, April 2019, pp.278-280, URL: http://www.ijtsrd.co $\mathrm{m} /$ papers/ijtsrd217 46.pdf

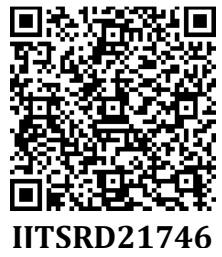

Copyright (C) 2019 by author(s) and International Journal of Trend in Scientific Research and Development Journal. This is an Open Access article distributed under the terms of the Creative Commons

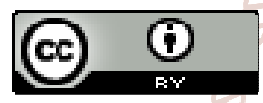
Attribution License (CC BY 4.0) (http://creativecommons.org/licenses/ by/4.0)

\section{INTRODUCTION}

Now a day's electrical supply industries is undergoing transforming worldwide. We are focusing on the sources for generating electricity and fulfill the gap between supply and demand, as we know that many power get lost in transmission of power via transmission line. So Flexible AC transmission system can give us benefits by expanding power transferring capabilities and power flow control adaptability of the transmission line.

These are the semi-state converters that have the capability to regulate the various electrical parameters in transmission circuits. They are to boot known as as FACTS controllers. Controllers incorporate thyristor control series compensator (TCSC), Static var Compensator (SVC), Unified power flow controller (UPFC), Static compensator (STATCOM), then forth. To remunerate the inductive reactance of the line thyristor control series compensator is associated in arrangement with the line. The SVC is utilized to assimilate or create receptive power by methods for thyristor controlled components. The Unified power Flow controller (UPFC) is able to give dynamic and responsive power control and control the magnitude of voltage level. It direct all the 3 factors at the same time.

\section{FACTS Controllers:-}

When we talk about the controllers in the FACTS then it can be defined as "it is the combination of power electronics and other static system which provide the control over the different parameter in our electrical system like current, voltage, power, reactance etc.

Now coming to its various types, it has four types:-

$>$ Series controllers

$>$ Shunt controllers

$>$ Combination of series-series controllers

$>$ Combination of series-shunt controllers

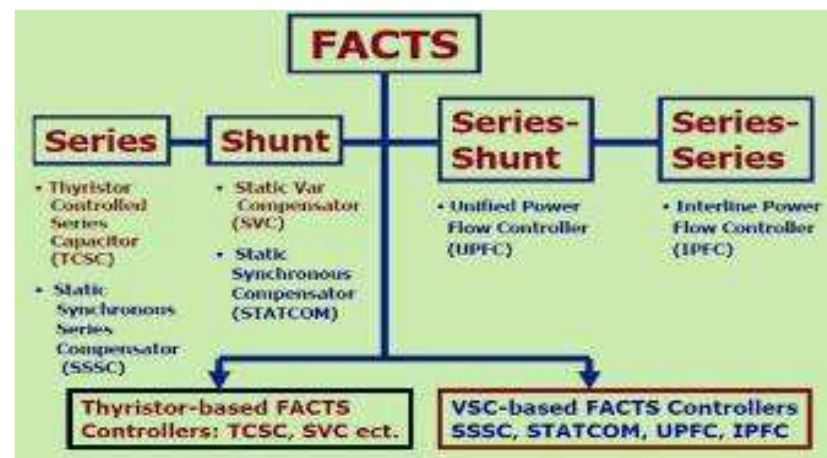

Fig. no-1 (Types of FACTS controllers)

1. Series controllers:-

It may be variable electrical phenomenon, for instance, capacitor, reactor so forth or an influence gadgets based mostly variable supply associated in arrangement with the line. All series controllers infuse voltage within the 
arrangement with the line. For no matter length of your time that the voltage is in stage quadrature with the line current, the arrangement controller simply supplies or expend responsive power, on the off likelihood that another stage association occur, at that time it devour or offer real capability to the line. We should see the diagram of the series controllers.

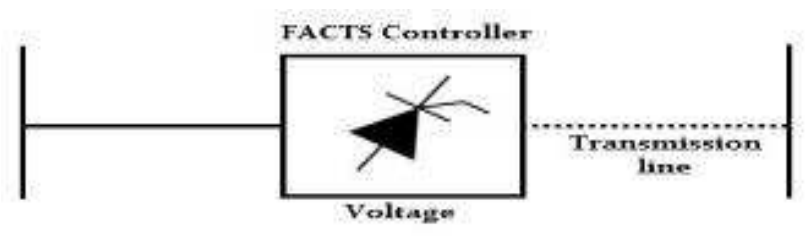

Fig. no-2 (Series controller)

\section{Thyristor controlled series capacitor (TCSC):-}

It contain of the series compensating capacitor shunted by a thyristor controlled reactor (TCR). Its elementary thought of TCSC is to offer a perpetually variable capacitance by mean of largely dropping the variable remunerating capacitance by the TCR. The TCR at the essential frequency may be a variable reactance. Impedance, affected by delay angle (alpha), steady-state reactance of TCSC is that of parallel of LC circuit, comprising of mounted capacitive reactance, XC and a variable reactance inductive reactance $\mathrm{XL}$. The TCSC may be a tunable parallel LC circuit to the line that's a gradual work current supply.

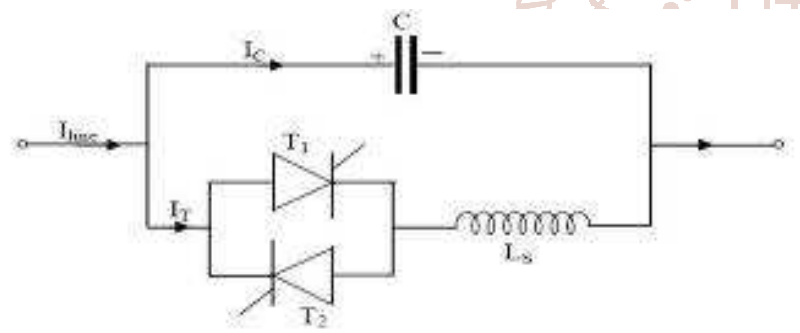

Fig. no-3 (Thyristor controlled series capacitor)

II. Static synchronous series compensator (SSSC):It is voltage source device based mostly compensator referred to as static synchronous series compensator (SSSC), within which the steady state management of transmission line will be designed up if the series compensator is given by a synchronous AC voltage supply (SVS), whose yield voltage coordinate voltage of the series condenser.

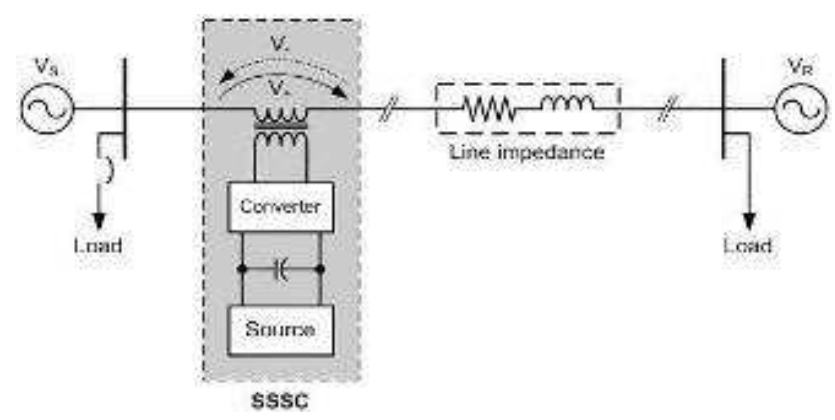

Fig. no-4 (Static synchronous series compensator)

2. Shunt controllers:-

It might be a variable impedance, variable supply or a combination of both, that infuse current into the framework at the aim of association. For no matter length of your time that the infused current is in part construction with the line voltage, the shunt controller simply provide or devour the variable receptive power and alternative case can include real power.

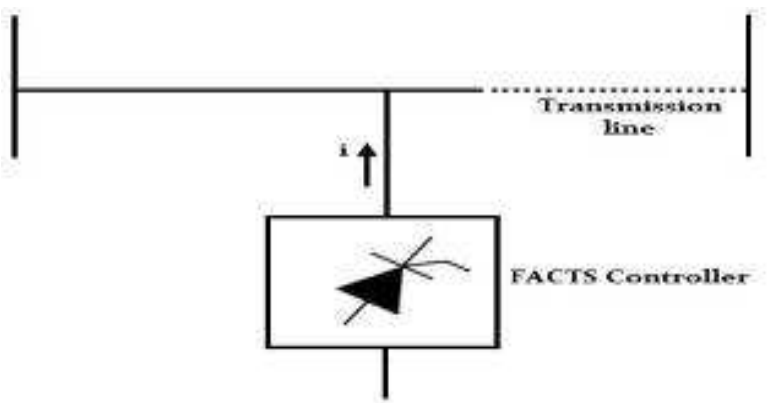

Fig. no-5 (Shunt controllers)

\section{Static Variable Compensator (SVC):-}

It is static variable generators whose yield is changed in order to keep up or control explicit parameters of the electrical power system. The essential outside control structure that characterizes the practical activity of the compensator and to this end infers the important contributions for the variable generator, s considerably a similar autonomous of the sort of factor generator utilized.

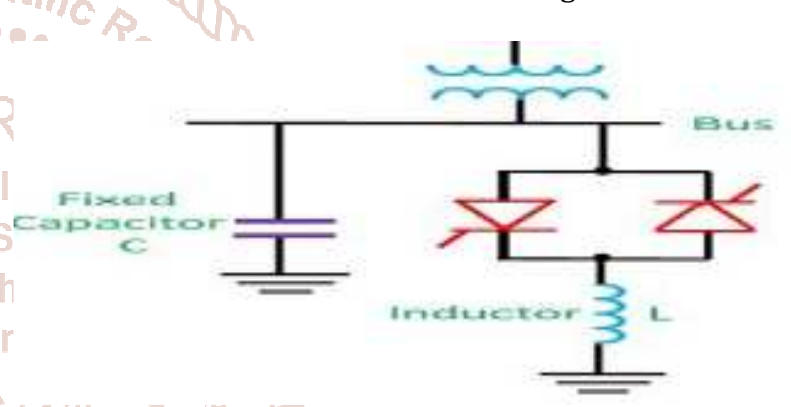

Fig. no-6 (Static Variable Compensator)

The essential target of applying a SVC in the power framework is to build the framework transmission capacity with the given transmission organize from the generators to the heaps. As the Static compensators can't create or assimilate real power, the power transmission of the framework s influenced by implication by voltage control.

The receptive power yield (capacitive or inductive) of the compensator is differed to control the voltage at given terminals of the transmission arrange in order to keep up the ideal power stream under conceivable framework unsettling influences.

\section{Static Synchronous Compensator (STATCOM):-}

It is a shunt-associated receptive power compensation device that is equipped for creating or engrossing reactive power. It is a solid state exchanging converter equipped for producing or engrossing independently controllable real and reactive power at its yield terminals, when it is sustained from a energy source or energy stockpiling gadget at its information terminals. The STATCOM is a voltage-source converter that, from a give DC voltage creates a set of 3-stage AC voltage yield each in stage with and coupled to the comparing AC framework voltage through a generally little reactance. The DC voltage is given by a energy source capacitor. 


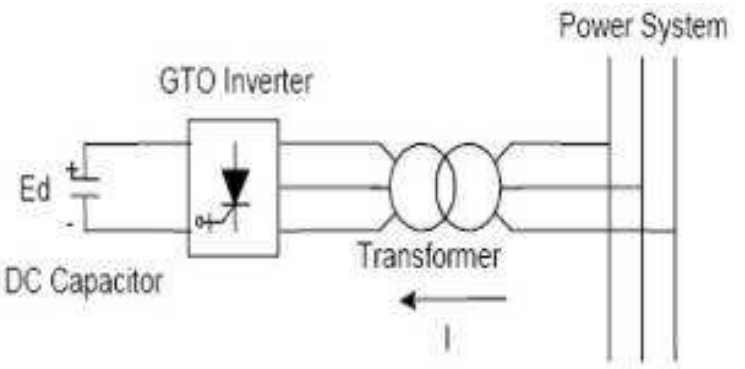

Fig. no-7 (Static synchronous compensator)

\section{Combined Series-Shunt Controllers:-}

It tends to be a mix of independent series and shunt controllers which are controlled in an organized way or a bound together power flow controller with series and shunt components. The shunt controllers infuse the current in the framework where as the series controllers infuse the voltage in arrangement to the line. At the point when the shunt and arrangement controllers are brought together then the real power trade between the series and shunt controllers by means of intensity interface.

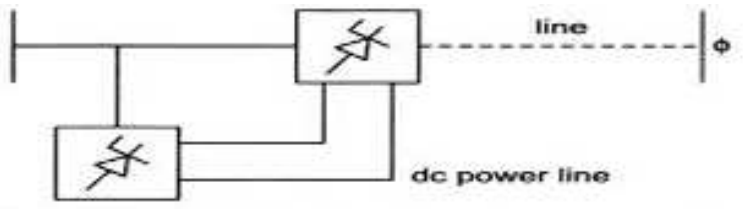

Fig. no-7 (Combination of Series-Shunt controllers)

I. Unified power Flow Controller (UPFC):-

It is associate device that provides fast-acting reactive power compensation on high voltage electricity transmission networks. It uses a combine of 3 parts governable bridges to provide current that $\mathrm{s}$ injected into the cable employing a series electrical device. The management will ready to control the flow of active and reactive power flow within the system cable. It uses solid-state devices, which give purposeful flexibility, typically not possible by standard thyristor controlled systems. It's combination of STATCOM and SSSC coupled via common DC voltage link.

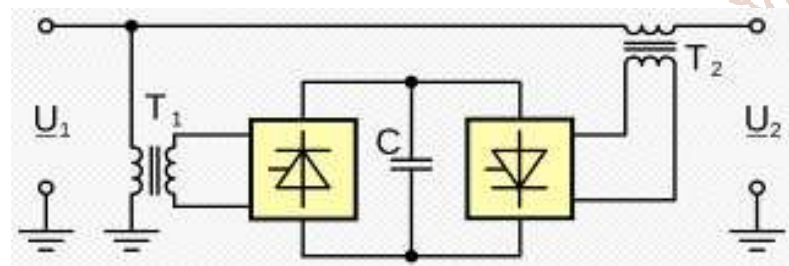

Fig. no-8 (Unified Power Flow Controller)

4. Combined series-series controllers:-

It may be a combination of independent series controllers, which are associated in facilitated way in a multi-line transmission framework or it tends to be a brought together controller.

In this arrangement of controller series controllers give free arrangement responsive remuneration to each line yet in addition exchange genuine power among the lines through a power interface. The real power transfer capability of the unified series-series controller, referred to the interline power flow controller (IPFC), which make it conceivable to adjust both the real and reactive power stream in the lines that is the reason it limit the usage of the Transmission framework

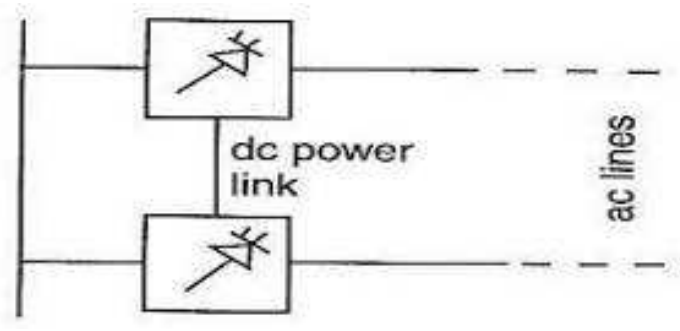

Fig. no-6 (Unified Series-Series controllers)

I. Interline Power Flow Controller (IPFC):-

It comprises of a lot of converters that are associated in series with the different transmission lines. It likewise incorporates a shunt converter which is associated between the transmission line the ground, these converters are associated in like manner DC connect to trade the dynamic power. Every series converter give free receptive pay of its own transmission line, if a shunt converter is engaged with this framework, the series converter give autonomous dynamic remuneration, generally not all the series converter give autonomous responsive pay of its own line.

Contrasted with the UPFC, the IPFC give a moderately practical answer for different transmission line control stream control, as just a single shunt converter is engaged with it. The IPFC additionally acquire control capacity than static synchronous series compensator (SSSC), which resembles the IPFC however SSSC is without the normal DC connect due to the dynamic remuneration.

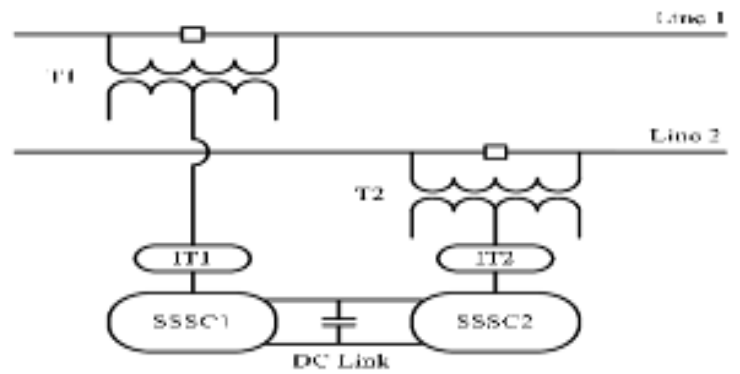

Fig. no-7 (Interline Power Flow Controller) 